\title{
BMJ Global Health Epidemiological transition in morbidity: 10-year data from emergency consultations in Dakar, Senegal
}

\author{
Bamba Gaye, ${ }^{1,2,3}$ Massamba Diop, ${ }^{4}$ Kumar Narayanan, ${ }^{5}$ Lucile Offredo, ${ }^{1}$ \\ Peter Reese, ${ }^{6}$ Marie Antignac, ${ }^{1}$ Vasenta Diop, ${ }^{4}$ Ahmadoul Badaviyou Mbacké, ${ }^{3}$ \\ Louise Boyer Chatenet, ${ }^{1}$ Eloi Marijon, ${ }^{1,2}$ Archana Singh-Manoux, ${ }^{7}$ \\ Ibrahima Bara Diop, ${ }^{8}$ Xavier Jouven ${ }^{1,2}$
}

\begin{abstract}
To cite: Gaye B, Diop M, Narayanan $\mathrm{K}$, et al. Epidemiological transition in morbidity: 10-year data from emergency consultations in Dakar, Senegal. BMJ Global Health 2019;4:e001396. doi:10.1136/ bmjgh-2019-001396
\end{abstract}

Handling editor Sanni Yaya

- Additional material is published online only. To view please visit the journal online (http://dx.doi.org/10.1136/ bmjgh-2019-001396).

$B G$ and $M D$ contributed equally.

Received 5 January 2019 Revised 29 April 2019 Accepted 25 May 2019

Check for updates

\section{(c) Author(s) (or their} employer(s)) 2019. Re-use permitted under CC BY-NC. No commercial re-use. See rights and permissions. Published by BMJ.

For numbered affiliations see end of article.

\section{Correspondence to}

Dr Bamba Gaye;

m.bamba.gaye@gmail.com

\section{ABSTRACT}

Background It is thought that low-income countries are undergoing an epidemiological transition from infectious to non-communicable diseases; however, this phenomenon is yet to be examined with long-term data on morbidity. Methods We performed a prospective evaluation of all emergency medical consultations at a major emergency service provider in Dakar, Senegal from 2005 to 2014. Using standardised definitions, the primary diagnosis for each consultation was classified using the International Classification of Diseases-10 and then broadly categorised as 'infectious', 'non-communicable' and 'other' diseases. Morbidity rates for each year in the 10-year observation period were plotted to depict the epidemiological transition over time. To quantify the yearly rate ratios of non-communicable over infectious diagnosis, we used a generalised Poisson mixed model.

Results Complete data were obtained from 49702 visits by African patients. The mean age was $36.5 \pm 23.2$ and $34.8 \pm 24.3$ years for women and men, respectively. Overall, infections accounted for $46.3 \%$ and $42.9 \%$ and non-communicable conditions $32.2 \%$ and $40.1 \%$ of consultations in women and men, respectively. Consultation for non-communicable compared with infectious conditions increased by $7 \%$ every year $(95 \% \mathrm{Cl}$ : $5 \%$ to $9 \% ; p<0.0001$ ) over the 10 years. Consultations for non-communicable condition were more likely in women compared with men ( $\mathrm{RR}=1.29,95 \% \mathrm{Cl}: 1.18,1.40)$ and at older ages ( $\mathrm{RR}=1.27 ; 95 \% \mathrm{Cl} 1.25,1.29$ for 10 -year increase in age).

Conclusion Using high-quality disease morbidity data over a decade, we provide novel data showing the epidemiological transition of diseases as manifested in emergency service consultations in a large Sub-Saharan African city. These results can help reorientation of healthcare policy in Sub-Saharan Africa.

\section{INTRODUCTION}

Non-communicable diseases are the leading causes of death in high-income countries, ${ }^{1}$ while both non-communicable and infectious diseases co-exist in low and middle-income countries. Recent data highlight the

\section{Key questions}

\section{What is already known?}

- Low-income countries are undergoing an epidemiological transition from infectious to non-communicable diseases.

- However, this phenomenon is yet to be examined with long-term data on morbidity.

\section{What are the new findings?}

- Using high-quality disease morbidity data over a decade, we provide novel data showing evidence for an epidemiological transition whereby emergency consultations for non-communicable diseases increased, overtaking infectious conditions as causes of emergency medical care in a large Sub-Saharan African city.

- In women, there was evidence that non-communicable conditions were already the primary causes of emergency consultations by 2010 while a similar trend was observed in men although infectious diseases continued to be more important even in 2014

What do the new findings imply?

- These data suggest a need for a focused reorientation of healthcare policy to combat the rising burden of non-communicable disease in Sub-Saharan Africa.

- By depicting age-stratified and sex-stratified patterns of healthcare utilisation in a leading centre for emergency department services, it is better able to show changes in the relative burden of different diseases in order to anticipate future trends and therefore provides a roadmap for healthcare planning and resource allocation.

increasing contribution of non-communicable diseases to burden of disease in low-income countries. $^{2}$ It has also been shown that the epidemiological transition has occurred in Ghana and factors other than socioeconomic status and drinking water source are responsible for the observed declines in mortality and fertility observed during the 
protracted epidemiological transition. ${ }^{2}$ However, most of the evidence for this 'epidemiological transition' comes from data on mortality as morbidity outcomes are poorly measured, particularly in Africa where the infrastructure does not allow accurate assessment of disease prevalence. Sub-Saharan Africa suffers from an acute lack of data, as highlighted by the recent Global Burden of Disease (GBD) studies. Data on morbidity outcomes is mostly confined to records from individual hospitals ${ }^{34}$ or autopsy reports ${ }^{5}$ which are on a small number of patients. Besides the mortality burden, better understanding changes in morbidity patterns is essential for effective healthcare policy.

Africa is undergoing rapid urbanisation and is therefore poised to witness major population shifts with over $50 \%$ of the population living in urban areas by 2030. Nearly a billion people will be living in urban areas, requiring appropriate redirection of public health measures. 6 The aim of the present study was to characterise changes in morbidity over a 10-year period in Dakar, Senegal. We used high quality data over time derived from consecutive visits to the SOS Medecins-the largest emergency service $(>100000)$ in a Sub-Saharan African city. Standardised case definitions as well as International Classification of Diseases (ICD-10) classification ensure robust, detailed data on underlying reason for the medical consultation. The analysis of trends in disease over a decade aims to examine whether the epidemiological transition observed for mortality also applies to morbidity.

\section{METHODS \\ Data}

We extracted data on all emergency medical consultations over a 10-year period (from 1 January 2005 to 31 December 2014) using records of SOS Medecins, the largest provider of such services in Senegal. This service was established in 1997, and it maintains rigorous standards, with an ISO9001 international quality certification. SOS Medecins Dakar is operational at all times (24 hours a day, 7 days a week) and comprises 8 emergency physicians, 11 anaesthesiologists and 4 cardiologists. It offers mobile emergency consultations and ambulance transport with a physician or paramedic. A standardised protocol is used to document each consultation, details are entered into the SOS Medecins database by the attending doctor creates who enters a provisional diagnosis. Three days later, a final diagnosis is ascertained using additional data (phone-call to discharged patients and review of medical record). Persons who died after admission or after a home-based consultation were not included in this study. SOS Medecins is recommended by most embassies, international medical assistance companies and other international organisations. The SOS Medecins database is a robust source of information on patients who seek emergency care for diverse medical conditions in Dakar.

\section{Statistical analyses}

For this study, data for all consecutive medical consultations handled by SOS Medecins in Dakar were obtained by a dedicated team of physician researchers. Comprehensive demographic information, including age, ethnicity (African vs other (American, Asian, European, other)), sex and instigator of the consultation (family or patient) were collected. The type of service provided (telephone consultation, home visit to see the patient, ambulance transport, emergency transport) were also obtained. For our analyses, the final diagnosis with an ICD-10 classification were then assigned to three broad groups: 'infectious' (respiratory infections, gastroenteritis/diarrhoea, malaria and other infectious diseases), 'non-communicable' (cardiovascular disease, neurological and psychiatric conditions, non-communicable non-infective pulmonary and gastrointestinal disorders) and 'other' (mainly trauma and accidents/injuries).

While data were obtained on patients of all ethnic origins, the focus of our analyses on the epidemiological transition was restricted to data from Africans. We first examined the unadjusted rates of consultations for non-communicable, infectious and other diseases over the entire observation period in women and men as a function of age in 10-year bands. We then examined unadjusted rates of the three main disease categories for each year between 2005 and 2014.

We used a generalised Poisson mixed model (corrected for over dispersion) to quantify the yearly rate ratios of non-communicable compared with infectious disease diagnosis in the consultations over the 10 -year period (2005 to 2014). These models take into account the correlation between multiple consultations by patients over the 10-year period. The total number of diagnoses was used as the offset in the Poisson model. The covariates in the model included age of the patient (10-year bands), sex and year of consultation (2005 to 2014). In further analyses, analysis stratified by sex, age group $(<40$, $40-70$ and $>70$ years) and time-period was conducted and an interaction term used to assess differences between sub-groups. All statistical analyses were performed at the Paris Cardiovascular Research Center (Inserm U970) using SAS V.9.4.

\section{Patient and public Involvement statement}

Patients were not involved in the study.

\section{RESULTS}

The study flowcharts is detailed in online supplementary figure 1. A total of 108736 medical consultations were undertaken by SOS Medecins in Dakar over the 10 -year observation period. Consultations with missing and/or incomplete data on sex of the patient $(n=181)$, age $(n=570)$, instigator of the consultation $(n=965)$ and diagnosis for the consultation $(n=8587)$ were excluded from the analyses. The follow-up success rate for final diagnosis 3 days later, was close to $100 \%$. Complete data 
were obtained from a total of 98433 consultations, out of which 49702 consultations were by patients who were African. Demographic data are shown in table 1. The mean age of patients was $36.5 \pm 23.2$ and $34.8 \pm 24.3$ years for African women and men, respectively, with $44.6 \%$ of these consultations being in men.

Table 1 provides further detailed descriptive data on ICD-10 diagnostic categories, stratified by sex. These aggregate data from all 10 years of observation show infectious diseases to account for $42.86 \%$ of all consultations in female patients and $46.25 \%$ in male patients. Most consultations in Africans were instigated by family members $(62.4 \%$ consultations in women and $59.7 \%$ in men), a smaller proportion by the patients themselves (18.5\% consultations in women and $14.9 \%$ in men). Most of the care provided was handled by the emergency medical team, with about $10 \%-15 \%$ of cases transported to other locations, such as a hospital. For the overall study period, infections accounted for $42.9 \%$ and $46.3 \%$ of diagnoses in women and men, respectively. The corresponding prevalence for non-communicable conditions were $40.1 \%$ and $32.2 \%$, respectively, while other conditions accounted for $17.1 \%$ and $21.6 \%$ in women and men, respectively.

We first examined all consultations in Africans grouped under infectious, non-communicable and other categories as a function of age of the patient, categorised in 10-year age bands. In both women and men (figure 1, panels $\mathrm{A}$ and $\mathrm{B}$, respectively), the primary cause of consultations at younger ages was infectious diseases with a transition to non-communicable diseases at older ages. These data show the transition to happen at the 40-49 age group in women (panel A) and the 50-59 age group in women (panel B). When men and women were combined (online supplementary figure 2), a similar pattern was observed with non-communicable diseases dominating the cause for consultation starting at the 40-49 age group.

Figure 2 depicts the same data for each of the 10 years in the observation period in women (panel A) and men (panel B). These data show that the epidemiological transition had not yet occurred among men by 2014, for whom visits for infections declined over the observation period but were still more frequent than non-communicable conditions (panel B, figure 1). Among women, the transition occurred around the year 2012, when visits for non-communicable conditions overtook infections (panel A, figure 1). In analyses not stratified by sex (online supplementary figure 3 ), the data show gradual decline in consultations for infections while the proportion of consultations for non-communicable diseases increased gradually, with the two curves converging in 2014.

Multivariable Poisson regression analysis (table 2) showed that consultations were more likely to be for non-communicable compared with infectious diseases, with a $7 \%$ (95\% CI 5\% to 9\%; p<0.0001) increased risk with every passing year in the observation period (2005 to 2014). Women compared with men were more likely to consult for non-communicable condition; this excess risk was $29 \%$ (95\% CI $18 \%$ to $40 \%$ ). The consultations in older patients was also more likely to be for care of non-communicable compared with infectious conditions, with a $27 \%$ (95\% CI $25 \%$ to $29 \%$ ) increased risk for every 10 -year age increment.

Analysis stratified by age group $(<40,40-70$ and $>70$ years) showed a consistent increase in consultations for non-communicable disease over the study period, irrespective of the age of the patient (table 2, lower half). However, higher rates of consultations for non-communicable diseases in women were not observed in the $\geq 70$ years age-group. When the analysis was restricted to only the first visit for each patient, similar results were obtained (data not shown). The changes across the 10 years on the percentages of each disease, in the overall population, and in Africans and non-Africans is presented in online supplementary tables 1-3, respectively. Online supplementary table 4 presents the distribution over time of patients served by SOS Medecins, by ethnicity/race.

\section{DISCUSSION}

This is the first study to systematically examine trends in morbidity over a decade in a large Sub-Saharan African city. Using data on consultations in a large, well-maintained medical emergency medical service in Dakar, we found in Africans (1) evidence for an epidemiological transition whereby emergency consultations for non-communicable diseases increased over the 10-year observation period, overtaking infectious conditions as causes of emergency medical care by the end of the observation period; (2) in women there was evidence that non-communicable conditions were already the primary causes of emergency consultations by 2010 while a similar trend was observed in men although infectious diseases continued to be more important even in 2014; (3) as expected, consultations in older patients were more likely to concern non-communicable diseases, with this transition evident in women starting at $40-49$ years and a decade later in men.

Sex differences in the trends in non-communicable diseases could not be examined in further detail due to unavailability of data on explanatory factors such as health or self-care behaviours. The cause underlying the consultations show higher rates for injury/external causes in men which may well explain sex differences. Diseases of the respiratory system accounted for a quarter of all consultations in women $(24.48 \%)$ and men $(25.79 \%)$. The recent rapid expansion of African cities is set to pose unique challenges for the provision of healthcare, with ultimately more people living in urban rather than rural areas. Changes in lifestyle and additional risks due to poor urban planning and lack of facilities may leave large numbers of people vulnerable to a variety of pathologies. It is important to note, very little cancer and other highburden non-communicable diseases are registered in this 
Table 1 Characteristics of consultations in an emergency medical centre in Dakar, Senegal

\begin{tabular}{|c|c|c|c|c|c|c|c|}
\hline & \multirow[b]{2}{*}{ ICD-10 } & \multicolumn{3}{|c|}{ Africans ( $n=49702)$} & \multicolumn{3}{|c|}{ Other $(n=48$ 731) } \\
\hline & & $\begin{array}{l}\text { Women } \\
(n=27529)\end{array}$ & $\begin{array}{l}\text { Men } \\
(n=22 \text { 173) }\end{array}$ & P value* & $\begin{array}{l}\text { Women } \\
(n=24571)\end{array}$ & $\begin{array}{l}\text { Men } \\
(n=24160)\end{array}$ & P value* \\
\hline \multicolumn{8}{|l|}{ ICD, n (\%) } \\
\hline $\begin{array}{l}\text { Infectious and parasitic } \\
\text { diseases }\end{array}$ & A00-B99 & 4049 (14.71) & $3450(15.56)$ & 0.0084 & $5128(20.87)$ & 4879 (20.19) & 0.0649 \\
\hline Neoplasms & C00-D48 & $11(0.04)$ & $4(0.02)$ & 0.1620 & $5(0.02)$ & $6(0.02)$ & 0.4718 \\
\hline $\begin{array}{l}\text { Diseases of the blood } \\
\text { and blood-forming } \\
\text { organs and certain } \\
\text { disorders involving the } \\
\text { immune mechanism }\end{array}$ & D50-D89 & $90(0.33)$ & $52(0.23)$ & 0.0550 & $20(0.08)$ & $23(0.1)$ & 0.6079 \\
\hline $\begin{array}{l}\text { Diseases of the nervous } \\
\text { system }\end{array}$ & G00-G99 & $314(1.14)$ & $319(1.44)$ & 0.0032 & $98(0.4)$ & $106(0.44)$ & 0.4952 \\
\hline $\begin{array}{l}\text { Diseases of the eye and } \\
\text { adnexa }\end{array}$ & $\mathrm{H} 00-\mathrm{H} 59$ & $147(0.53)$ & $116(0.52)$ & 0.8687 & $204(0.83)$ & $212(0.88)$ & 0.5709 \\
\hline $\begin{array}{l}\text { Diseases of the ear and } \\
\text { mastoid process }\end{array}$ & H60-H95 & $497(1.81)$ & $441(1.99)$ & 0.1350 & 1135 (4.62) & $1386(5.74)$ & $<0.0001$ \\
\hline $\begin{array}{l}\text { Diseases of the } \\
\text { circulatory system }\end{array}$ & $100-199$ & $1058(3.84)$ & $933(4.21)$ & 0.0394 & $236(0.96)$ & $371(1.54)$ & $<0.0001$ \\
\hline $\begin{array}{l}\text { Diseases of the } \\
\text { respiratory system }\end{array}$ & J00-J99 & $6739(24.48)$ & 5719 (25.79) & 0.0008 & 7588 (30.88) & 7337 (30.37) & 0.2188 \\
\hline $\begin{array}{l}\text { Diseases of the } \\
\text { genitourinary system }\end{array}$ & N00-N99 & $686(2.49)$ & $366(1.65)$ & $<0.0001$ & $765(3.11)$ & $546(2.26)$ & $<0.0001$ \\
\hline $\begin{array}{l}\text { Pregnancy, childbirth and } \\
\text { the puerperium }\end{array}$ & O00-099 & $99(0.36)$ & NA & NA & $42(0.17)$ & NA & NA \\
\hline $\begin{array}{l}\text { Congenital } \\
\text { malformations, } \\
\text { deformations and } \\
\text { chromosomal } \\
\text { abnormalities }\end{array}$ & Q00-Q99 & $1(0)$ & $1(0)$ & 0.8782 & $0(0)$ & $0(0)$ & l \\
\hline $\begin{array}{l}\text { Symptoms, signs and } \\
\text { abnormal clinical and } \\
\text { laboratory findings, not } \\
\text { elsewhere classified }\end{array}$ & R00-R99 & $6739(24.48)$ & 4625 (20.86) & $<0.0001$ & 3633 (14.79) & 3404 (14.09) & 0.0288 \\
\hline $\begin{array}{l}\text { Injury, poisoning } \\
\text { and certain other } \\
\text { consequences of } \\
\text { external causes }\end{array}$ & S00-T98 & $1921(6.98)$ & $2471(11.14)$ & $<0.0001$ & $1778(7.24)$ & $2113(8.75)$ & $<0.0001$ \\
\hline $\begin{array}{l}\text { Factors influencing } \\
\text { health status and contact } \\
\text { with health services }\end{array}$ & ZOO-Z99 & $880(3.2)$ & $873(3.94)$ & $<0.0001$ & $687(2.8)$ & $786(3.25)$ & 0.0032 \\
\hline Diagnostic group, n (\%) & & & & $<0.0001$ & & & $<0.0001$ \\
\hline
\end{tabular}


Table 1 Continued

\begin{tabular}{|c|c|c|c|c|c|c|c|}
\hline & \multirow[b]{2}{*}{ ICD-10 } & \multicolumn{3}{|c|}{ Africans ( $n=49702)$} & \multicolumn{3}{|c|}{ Other $(n=48731)$} \\
\hline & & $\begin{array}{l}\text { Women } \\
(n=27529)\end{array}$ & $\begin{array}{l}\text { Men } \\
(n=22 \text { 173) }\end{array}$ & P value* & $\begin{array}{l}\text { Women } \\
(n=24571)\end{array}$ & $\begin{array}{l}\text { Men } \\
(n=24 \text { 160) }\end{array}$ & P value* \\
\hline $\begin{array}{l}\text { Non-communicable } \\
\text { diseases }\end{array}$ & & $11036(40.09)$ & 7135 (32.18) & $<0.0001$ & $5791(23.57)$ & $5320(22.02)$ & $<0.0001$ \\
\hline Infectious diseases & & $11798(42.86)$ & $\begin{array}{l}10256 \\
(46.25)\end{array}$ & $<0.0001$ & $15540(63.25)$ & $15232(63.05)$ & 0.6490 \\
\hline Other diseases & & 4695 (17.05) & $4782(21.57)$ & $<0.0001$ & 3240 (13.19) & 3608 (14.93) & $<0.0001$ \\
\hline
\end{tabular}

${ }^{*} \mathrm{P}$ value of comparisons between men and women; the mapped ICD-10 to chronic disease is included in the online supplementary data.

ICD, International Classification of Diseases; NA, not applicable.

dataset. However, it is unclear whether cancer is primarily diagnosed in routine assessment or in emergency care in Sub-Saharan Africa. Our focus was consultations in emergency care, it is also possible that cancer prevalence is increasing in this region of the world.

The importance of our study on morbidity lies in the use of health resource utilisation rather than relying on self-report data morbidity or mortality data. Use of morbidity rather than mortality data to study the epidemiological transition in Africa provides a more accurate

\section{PANEL A}

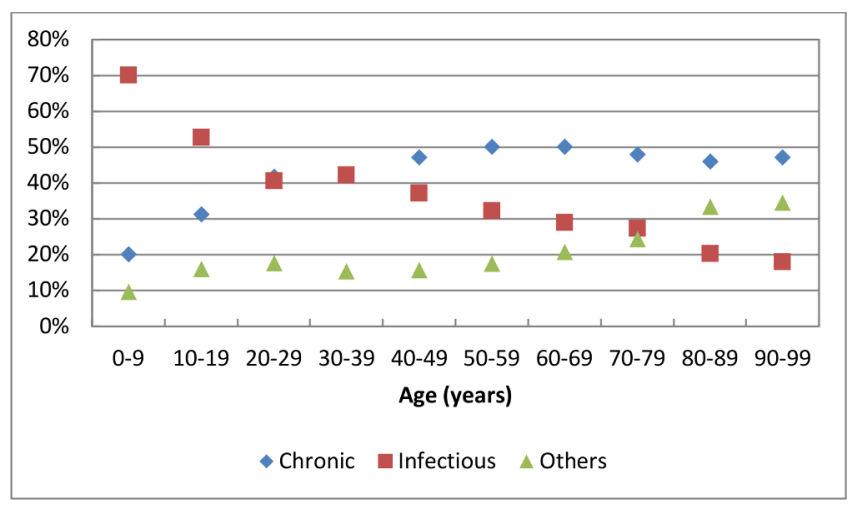

\section{PANEL B}

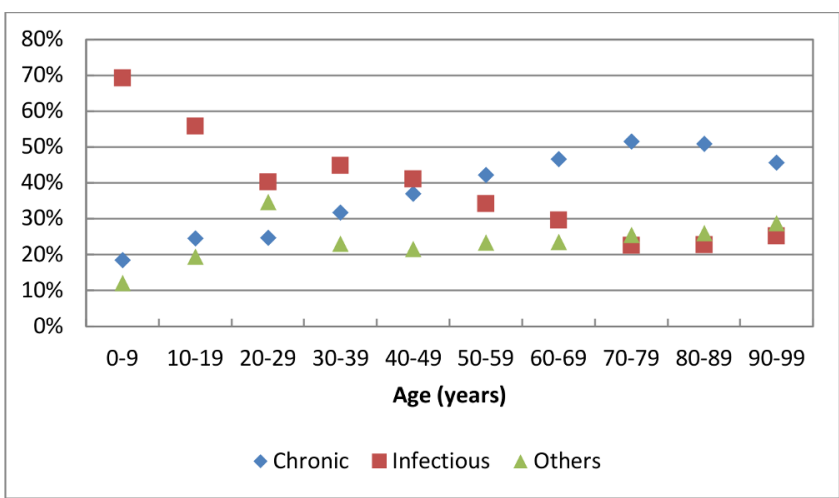

Figure 1 Broad diagnostic categories of emergency medical consultations by age-group in African women (PANEL A) and men (PANEL B). * Data on 27,529 consultations in African women and 22,173 consultations in African men over a 10-year period. indicator of current medical resource utilisation and needs. It is also more logical that healthcare policy and allocation priorities should be driven by information derived from morbidity, which represents an opportunity to plan ahead and intervene early. Trends in mortality are also affected by parallel advances in therapy and management. The GBD 2013 study reported an increase of only $1 \%$ in age-standardised cardiovascular mortality over two decades in the Sub-Saharan African region. However, this

PANEL A

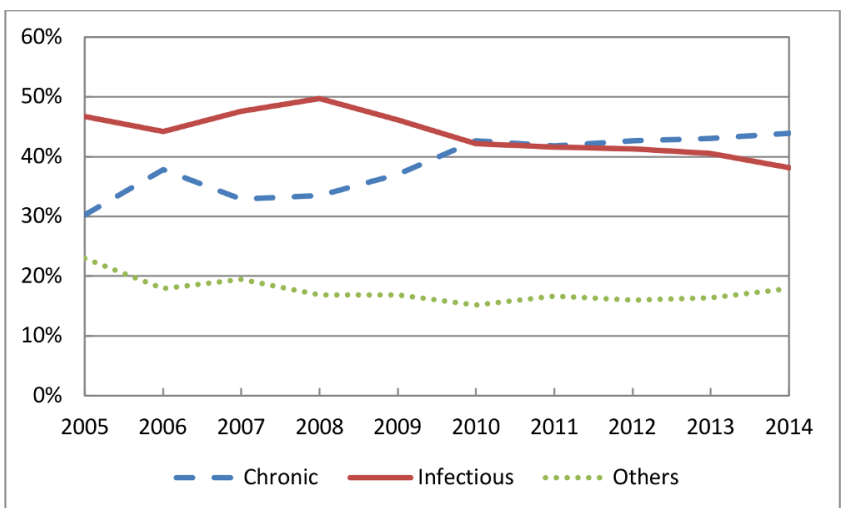

PANEL B

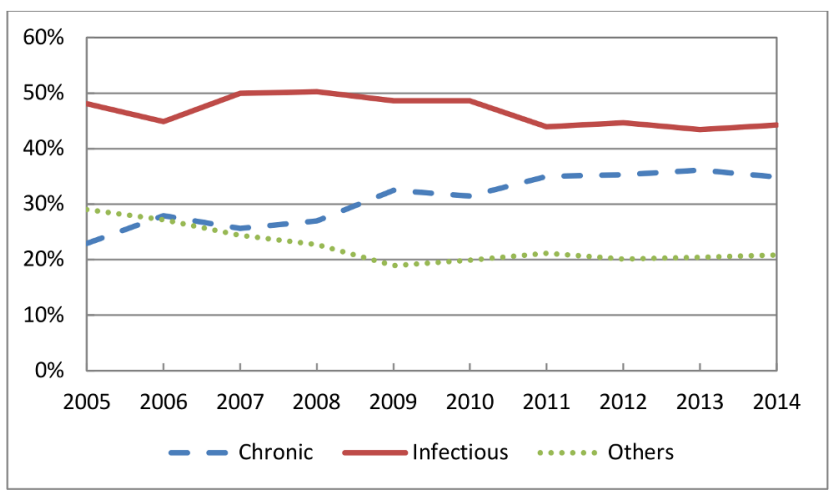

Figure 2 Broad diagnostic categories of emergency medical consultations in African women (PANEL A) and men (PANEL B) over 10 years in Dakar, Senegal. *Data on 27,529 consultations in African women and in 22,173 African men over a 10-year period. 
Table 2 Poisson mixed model regression for excess risk of non-communicable compared with infectious diagnosis in emergency medical consultations between 2005 and 2014

\begin{tabular}{|c|c|c|}
\hline & Risk ratio $(95 \% \mathrm{Cl})$ & $P$ value \\
\hline Year of consultation* & 1.07 (1.05 to 1.09$)$ & $<0.0001$ \\
\hline Female sex (vs male) & 1.29 (1.18 to 1.40$)$ & $<0.0001$ \\
\hline $\begin{array}{l}\text { Age of patient (10-year } \\
\text { increment) }\end{array}$ & 1.27 (1.25 to 1.29$)$ & $<0.0001$ \\
\hline \multicolumn{3}{|c|}{ Analysis stratified by age-group of patient } \\
\hline \multicolumn{3}{|l|}{$<40$ years } \\
\hline Year of consultation* & 1.07 (1.02 to 1.11$)$ & 0.003 \\
\hline Female sex (vs male) & 1.58 (1.25 to 1.99$)$ & $<0.0001$ \\
\hline \multicolumn{3}{|l|}{ 40-69 years } \\
\hline Year of consultation* & 1.07 (1.04 to 1.10$)$ & $<0.0001$ \\
\hline Female sex (vs male) & 1.27 (1.11 to 1.45$)$ & 0.005 \\
\hline \multicolumn{3}{|l|}{$\geq 70$ years } \\
\hline Year of consultation* & 1.06 (1.02 to 1.11$)$ & 0.002 \\
\hline Female sex (vs male) & 0.90 (0.73 to 1.11$)$ & 0.30 \\
\hline
\end{tabular}

${ }^{\star}$ Each additional year in the 10-year observation window.

figure conceals major changes in the pattern of cardiovascular disease occurring in this region. ${ }^{7}$

From a health perspective, Sub-Saharan Africa is one of the most vulnerable regions in the world due to worsening cardiovascular risk profile. In the past four decades, prevalence of hypertension decreased in high-income countries, such as North America and Europe, shifting these countries from the highest blood pressure strata in 1975 to the lowest by 2015 . By contrast, in Sub-Saharan Africa, the number of adults with raised blood pressure has alarmingly increased from 0.59 to 1.13 billion between 1975 and 2015, especially in low-income and middle-income countries. During the same period, Africa and Sub-Saharan Africa in particular has witnessed an exponential rise in cardiovascular risk factors. Furthermore, premature cardiovascular mortality could reach $25 \%$ to $50 \%$ of all-cause mortality in these countries by 2025 , if the prevalence of risk factors continues to rise, with hypertension being the number one risk factor. In Sub-Saharan Africa, the number of adults with raised blood pressure has alarmingly increased from 0.59 to 1.13 billion between 1975 and 2015, especially in low-income and middle-income countries. Paradoxically, it also the region where the least amount of data on health is available despite the need for such data for planning effective healthcare delivery. The GBD studies $\mathbf{2}$ are a valuable resource but they often rely on extrapolated estimates from across diverse healthcare environments to predict the incidence of a given disease in a region, especially for regions such as Sub-Saharan Africa. Few studies have systematic data to assess the epidemiological transition in morbidity patterns in Sub-Saharan Africa. Most studies are small scale and focus mainly on cardiovascular disease; examples are studies in Soweto, South
Africa, ${ }^{8-10}$ Nairobi, Kenya, ${ }^{11}$ Nigeria,${ }^{12}$ Lome, Togo ${ }^{4}$ and Ethiopia.13 We took a systematic approach to the assessment of all medical consultations over a 10 -year period in order to draw conclusions on the epidemiological transition in morbidity.

The present study has important public health implications.14-16 By depicting age-stratified and sex-stratified patterns of healthcare utilisation in a leading centre for emergency department services, it is better able to show changes in the relative burden of different diseases in order to anticipate future trends and therefore provides a roadmap for healthcare planning and resource allocation. For instance, the WHO and UN have launched an international initiative aiming to reduce the global burden of hypertension, diabetes and obesity by $25 \%$ and to reduce the cardiovascular mortality by $25 \%$ by 2025. ${ }^{17} 18$ A restructuring of health policy, long-term commitments ${ }^{19}$ and a multi-pronged strategy comprising effective primary healthcare delivery and campaigns to promote healthy lifestyles are needed to combat the rising burden of non-communicable diseases. 20

\section{Limitations}

An important limitation of our study is the use of a single database, SOS Medecins Dakar, to study the epidemiological transition in morbidity. Despite this study being based on the largest database of emergency medical consultations in Senegal, the extent to which it is fully representative of healthcare utilisation in emergency medicine setting in West African urban settings is unclear as other emergency care services were not included in this study due to lack of documentation in these services. Data were derived from one city and it is possible that disease patterns and resource utilisation in other regions and more rural areas may be different. A further limitation is that $8.7 \%$ consultations could not be included in the analyses due to missing or incomplete diagnosis. However, we did not find any reason to assume these dropped terms may have differed from the total sample. These persons are similar in age, and proportion of men/ women and African/non-African.

\section{CONCLUSION}

Using disease morbidity data over a decade in an emergency medicine setting, we have for the first time examined the epidemiological transition in a large Sub-Saharan African city. These data suggest a need for a focused reorientation of healthcare policy to combat the rising burden of non-communicable disease in Sub-Saharan Africa.

\footnotetext{
Author affiliations

${ }^{1}$ Université de Paris, INSERM, Paris Cardiovascular Research Centre, Paris, France ${ }^{2}$ Cardiology Department, Georges-Pompidou European Hospital, 56, rue Leblanc, Paris, France

${ }^{3}$ UFR des Technologies et des Métiers, Université Cheikh Ahmadoul Khadim (UCAK) de Touba, Diourbel, Senegal

${ }^{4}$ S.O.S Medecin Sénégal, Dakar, Senegal

${ }^{5}$ Cardiology Department, Maxcure Hospitals, Hitec City, India
} 
${ }^{6}$ Department of Biostatistics, Epidemiology, and Informatics, Perelman School of Medicine, University of Pennsylvania, Philadelphia, Pennsylvania, USA ${ }^{7}$ INSERM, U1153, Epidemiology of Ageing and Neurodegenerative diseases, Université Paris-Descartes, Paris, France

${ }^{8}$ Cardiology Department, University Hospital of Fann, Dakar, Senegal

Contributors $\mathrm{BG}, \mathrm{MD}$ and $\mathrm{XJ}$ had full access to all the data in the study and take responsibility for the integrity of the data and the accuracy of the data analysis. Study concept and design: MD, XJ. Acquisition, analysis or interpretation of data: BG, MD, KN, PR, VD, ABM, LBC, MA, LO, EM, AS-M, IBD, XJ. Drafting of the manuscript: $B G, K N$. Critical revision of the manuscript for important intellectual content: BG, MD, KN, PR, VD, ABM, LBC, MA, LO, EM, AS-M, IBD, XJ. Statistical analysis: BG, LO. Study supervision: BG, MD, XJ.

Funding The authors have not declared a specific grant for this research from any funding agency in the public, commercial or not-for-profit sectors.

Competing interests None declared.

Patient consent for publication Not required.

Ethics approval Ethics approval for the study was obtained from the National Ethical Committee of Senegal (Number 4864602).

Provenance and peer review Not commissioned; externally peer reviewed.

Data availability statement Data are available upon reasonable request.

Open access This is an open access article distributed in accordance with the Creative Commons Attribution Non Commercial (CC BY-NC 4.0) license, which permits others to distribute, remix, adapt, build upon this work non-commercially, and license their derivative works on different terms, provided the original work is properly cited, appropriate credit is given, any changes made indicated, and the use is non-commercial. See: http://creativecommons.org/licenses/by-nc/4.0/.

\section{REFERENCES}

1. Global, regional, and national age-sex specific all-cause and causespecific mortality for 240 causes of death, 1990-2013: a systematic analysis for the global burden of disease study 2013. The Lancet 2015;385:117-71.

2. Murray CJL, Barber RM, Foreman KJ, et al. Global, regional, and national disability-adjusted life years (DALYs) for 306 diseases and injuries and healthy life expectancy (HALE) for 188 countries. The Lancet 2015;386:e45:2117-226.

3. Yayehd K, Damorou F, N'Da NW, et al. [Evolution of cardiovascular diseases' admissions in cardiology departments of Lomé hospitals: a cross-sectional study on 7959 patients from June 2004 to May 2009]. Rev Epidemiol Sante Publique 2012;60:205-11.

4. Soliman EZ, Juma H. Cardiac disease patterns in northern Malawi: epidemiologic transition perspective. J Epidemiol 2008;18:204-8.
5. Erete El, Ogun OG, Oladapo OO, et al. Prevalence and severity of atherosclerosis in extra cranial carotid arteries in Nigeria: an autopsy study. BMC Cardiovasc Disord 2012;12:106.

6. Lall SV, Henderson JV, Venables AJ. Africa's Cities : Opening Doors to the World. [Internet]. Washington, DC: World Bank, 2017. Available: https://openknowledge.worldbank.org/handle/10986/ 25896

7. Mensah GA, Roth GA, Sampson UKA, et al. Mortality from cardiovascular diseases in sub-Saharan Africa, 1990-2013: a systematic analysis of data from the global burden of disease study 2013: cardiovascular topic. Cardiovasc J Afr 2015;26:S6-S10.

8. Sliwa K, Wilkinson D, Hansen C, et al. Spectrum of heart disease and risk factors in a black urban population in South Africa (the heart of Soweto study): a cohort study. The Lancet 2008;371:915-22.

9. Tibazarwa K, Ntyintyane L, Sliwa K, et al. A time bomb of cardiovascular risk factors in South Africa: results from the Heart of Soweto Study "Heart Awareness Days". Int J Cardiol 2009;132:233-9.

10. Sliwa K, Carrington MJ, Klug E, et al. Predisposing factors and incidence of newly diagnosed atrial fibrillation in an urban African community: insights from the heart of Soweto study. Heart 2010;96:1878-82.

11. Shavadia J, Yonga G, Mwanzi S, et al. Clinical characteristics and outcomes of atrial fibrillation and flutter at the Aga Khan university Hospital, Nairobi. Cardiovasc J Afr 2013;24:6-9.

12. Ojji DB, Ajayi SO, Mamven $\mathrm{MH}$, et al. Prevalence of metabolic syndrome among hypertensive patients in Abuja, Nigeria. Ethn Dis 2012;22:1-4.

13. Accorsi S, Kedir N, Farese P, et al. Poverty, inequality and health: the challenge of the double burden of disease in a non-profit hospital in rural Ethiopia. Trans R Soc Trop Med Hyg 2009;103:461-8.

14. Abuya T, Ochola S, Mutemi W, Fegan G, Rowa Y, et al. Impact of Ministry of health interventions on private medicine retailer knowledge and practices on anti-malarial treatment in Kenya. Am J Trop Med Hyg 2009;80:905-13

15. Kandala N-B, Stranges S. Geographic variation of overweight and obesity among women in Nigeria: a case for nutritional transition in sub-Saharan Africa. PLoS One 2014;9:e101103.

16. Golzarand M, Mirmiran $P$, Jessri $M$, et al. Dietary trends in the middle East and North Africa: an ecological study (1961 to 2007). Public Health Nutr 2012;15:1835-44.

17. Nulu S, Aronow WS, Frishman WH. Hypertension in sub-Saharan Africa: a contextual view of patterns of disease, best management, and systems issues. Cardiol Rev 2016;24:30-40.

18. Organization WH. Global action plan for the prevention and control of noncommunicable diseases 2013-2020, 2013. Available: http:// apps.who.int/iris/bitstream/10665/94384/5/9789244506233_rus.pdf [Accessed 9 Aug 2017].

19. Aantjes CJ, Quinlan TKC, Bunders JFG. Practicalities and challenges in re-orienting the health system in Zambia for treating chronic conditions. BMC Health Serv Res 2014;14:295.

20. Greenberg H, Raymond SU, Leeder SR. Global health assistance for chronic illness: a look at the practical. Prog Cardiovasc Dis 2008;51:89-96. 